\title{
Caffeine does not significantly reduce the sensitivity of vasodilator stress MPI: Rebuttal
}

Whether caffeine affects the diagnostic performance of vasodilator stress myocardial perfusion scintigraphy (MPS) remains a matter for debate. ${ }^{1,2}$ Attenuation of stress-induced coronary vasodilation by caffeine was first demonstrated in studies using dipyridamole. In the "cons" position of the debate, Saab et al. argued that this early evidence cannot be generalized to adenosine and other related compounds because of the indirect and therefore variable vasodilator effect of dipyridamole. ${ }^{1}$ Experimental and clinical studies have shown that dipyridamole is not inferior to adenosine for inducing maximal or near-maximal coronary hyperemia with dipyridamole and adenosine MPS having similar sensitivity and predictive value for the detection of coronary artery disease. ${ }^{3}$ An increased susceptibility to caffeine because of a less consistent vasodilator effect is therefore unlikely. With regard to the effect of caffeine on adenosine MPS, two of the three studies addressing this issue showed no effect of caffeine on adenosine-induced perfusion abnormality. ${ }^{4,5}$ In these two studies, average plasma caffeine concentration was half the concentration attained in the only study documenting a positive effect. ${ }^{6}$ Of note, the levels of caffeine detected in this study were close to those reported in the early dipyridamole work. In all three studies, caffeine did not appear to affect the hemodynamic response to adenosine stress. In the positive study, the addition of exercise was a confounder; in the negative studies, no confounder is identified, which would support the argument for a suboptimal caffeine load as the likely explanation. Caffeine metabolism obeys first-order elimination kinetics at small amounts, but zero-order occurs at higher doses. ${ }^{7}$ This might partly explain the lack of a doseresponse relation for the extent of inducible perfusion abnormality observed in the only study investigating the effect of caffeine on regadenoson MPS. ${ }^{8}$ In this regard, Saab et al. argued that the observed changes in perfusion defect were small and within the reproducibility of serial imaging. The study however showed that these changes, albeit small, were significantly different from those expected from two consecutive stress MPS studies alone.

J Nucl Cardiol 2016;23:604

$1071-3581 / \$ 34.00$

Copyright (c) 2016 American Society of Nuclear Cardiology.
Moreover, additional analysis demonstrated that a nonnegligible proportion of patients moved to a lower ischemic category after caffeine intake, suggesting that the burden of disease could be underestimated in some individuals. In summary, there is currently no robust evidence to reject the hypothesis that caffeine can have a negative impact on the diagnostic performance of vasodilator MPS, especially at moderate to high concentrations. Until new data become available, caffeine consumption before vasodilator stress would be best avoided.

\section{Eliana Reyes, MD, PhD, FESC, (ه) Nuclear Medicine Department, Royal Brompton and Harefield Hospitals, Sydney Street, London \\ SW3 6NP, \\ United Kingdom; e.reyes@rbht.nhs.uk.}

\section{References}

1. Saab R, Bajaj N, Hage F. Caffeine does not significantly reduce the sensitivity of vasodilator stress myocardial perfusion imaging. J Nucl Cardiol 2016.

2. Reyes E. Caffeine reduces the sensitivity of vasodilator MPI for the detection of myocardial ischemia: Pro. J Nucl Cardiol 2016.

3. Loong CY, Anagnostopoulos C. Diagnosis of coronary artery disease by radionuclide myocardial perfusion imaging. Heart 2004;90:v2-v9.

4. Zoghbi GJ, Htay T, Aqel R, Blackmon L, Heo J, Iskandrian AE. Effect of caffeine on ischemia detection by adenosine single-photon emission computed tomography perfusion imaging. J Am Coll Cardiol 2006;47:2296-302.

5. Lee JC, Fraser JF, Barnett AG, Johnson LP, Wilson MG, McHenry $\mathrm{CM}$, et al. Effect of caffeine on adenosine-induced reversible perfusion defects assessed by automated analysis. J Nucl Cardiol 2012;19:474-81.

6. Reyes E, Loong CY, Harbinson M, Donovan J, Anagnostopoulos C, Underwood SR. High-dose adenosine overcomes the attenuation of myocardial perfusion reserve caused by caffeine. J Am Coll Cardiol 2008;52:2008-16.

7. Cheng WS, Murphy TL, Smith MT, Cooksley WG, Halliday JW, Powell LW. Dose-dependent pharmacokinetics of caffeine in humans: Relevance as a test of quantitative liver function. Clin Pharmacol Ther 1990;47:516-24.

8. Tejani FH, Thompson RC, Kristy R, Bukofzer S. Effect of caffeine on SPECT myocardial perfusion imaging during regadenoson pharmacologic stress: A prospective, randomized, multicenter study. Int J Cardiovasc Imaging 2014;30:979-89.

doi:10.1007/s12350-016-0421-7 